\title{
Papers
}

\section{Mortality among displaced former UNITA members and their families in Angola: a retrospective cluster survey}

\author{
Thomas Grein, Francesco Checchi, Josep M Escribà, Abiy Tamrat, Unni Karunakara, \\ Christopher Stokes, Vincent Brown, Dominique Legros
}

\begin{abstract}
Objective To measure retrospectively mortality among a previously inaccessible population of former UNITA members and their families displaced within Angola, before and after their arrival in resettlement camps after ceasefire of 4 April 2002.

Design Three stage cluster sampling for interviews. Recall period for mortality assessment was from 21 June 2001 to 15-31 August 2002.

Setting Eleven resettlement camps over four provinces of Angola (Bié, Cuando Cubango, Huila, and Malange) housing 149000 former UNITA members and their families.

Participants 900 consenting family heads of households, or most senior household members, corresponding to an intended sample size of 4500 individuals.

Main outcome measures Crude mortality and proportional mortality, overall and by period (monthly, and before and after arrival in camps).

Results Final sample included 6599 people. The 390 deaths reported during the recall period corresponded to an average crude mortality of $1.5 / 10000 /$ day (95\% confidence interval 1.3 to 1.8 ), and, among children under 5 years old, to

4.1/10 000/day (3.3 to 5.2). Monthly crude mortality rose gradually to a peak in March 2002 and remained above emergency thresholds thereafter. Malnutrition was the leading cause of death (34\%), followed by fever or malaria (24\%) and war or violence (18\%). Most war victims and people who had disappeared were women and children.

Conclusions This population of displaced Angolans experienced global and child mortality greatly in excess of normal levels, both before and after the 2002 ceasefire. Malnutrition deaths reflect the extent of the food crisis affecting this population. Timely humanitarian assistance must be made available to all populations in such conflicts.
\end{abstract}

\section{Introduction}

In Angola, 27 years of civil war between the ruling Movimento Popular de Libertação de Angola (MPLA) and the União Nacional para a Independência Total de Angola (UNITA) movement were tentatively ended by a ceasefire signed on 4 April 2002. The last phase of the war (1998-2002), characterised by "scorched earth" military strategies and an international embargo imposed on areas held by UNITA, rendered large areas of Angola inaccessible to international relief organisations. After the ceasefire, three million people were estimated to be in need of immediate aid. ${ }^{1}$ Several health assessments conducted among previously isolated populations showed alarming prevalences of malnutrition (32\% in Cuando Cubango province and $52 \%$ in Huila), with crude mortality reaching 2.3 deaths $/ 10$ 000/day in Huambo and 3.6/10 000/day in Moxico, ${ }^{2}$ far in excess of normal mortality in developing countries, estimated at $0.3-0.6 / 10000 /$ day. ${ }^{3}$ These data, along with observations of relief workers, strongly suggested that, among the inaccessible populations of Angola, a largely undocumented humanitarian disaster had unfolded.

Between April and August 2002, as part of the post-ceasefire demobilisation, about 81000 former members of UNITA and 230000 of their family members assembled in 35 resettlement camps countrywide. ${ }^{4}$ The medical relief organisation Médecins Sans Frontières launched nutritional and healthcare programmes in several of these. Below we report the findings of a retrospective mortality survey conducted in several former UNITA camps as part of an effort to document the effect of war on Angola's populations. The survey covered 14 months (June 2001 to August 2002), most of which was before the ceasefire. The main objectives were to measure crude mortality and mortality in children aged under 5 years, to identify major causes of death, and to describe the demographic evolution of the population.

\section{Participants and methods}

The study included all 11 camps of former UNITA members in the four provinces of Bié, Cuando Cubango, Huila, and Malange (fig 1). Covering a registered population of 149 106, the survey thus included $38 \%$ of the total estimated former UNITA population in 35 camps countrywide. All camps in the survey were administered by UNITA, and relied on external assistance for food and health care. Camp population varied from 4800 to 42000 people.
Epicentre, 8 rue Saint Sabin, 75011 Paris, France

Thomas Grein epidemiologist Francesco Checchi epidemiologist Vincent Brown epidemiologist Dominique Legros director

Médecins Sans Frontières, Nou de la Rambla, 26, 08001 Barcelona, Spain

Josep M Escribà epidemiologist

Médecins Sans Frontières, Rue du Lac 12, 1207 Geneva, Switzerland Abiy Tamrat operations desk officer

Médecins Sans Frontières, Max Euweplein 40, 1001 EA Amsterdam, Netherlands

Unni Karunakara health advisor

Médecins Sans Frontières, Dupréstraat 94 , 1090 Brussels, Belgium

Christopher Stokes operations director

Correspondence to: D Legros epimail@ epicentre.msf.org

bmj.com 2003;327:650

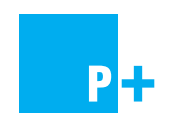

Copies of the survey manual and questionnaire used in this study are available on bmj.com 


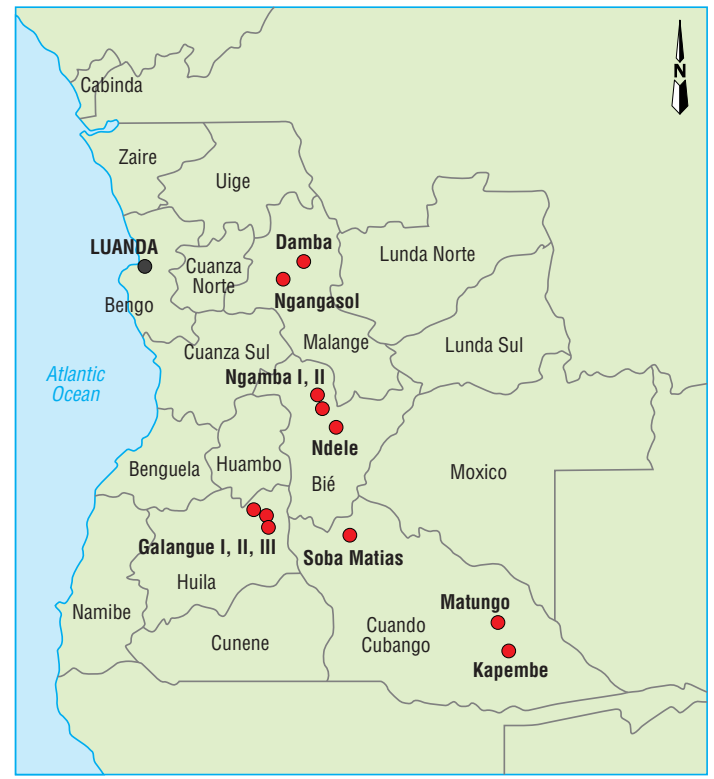

Fig 1 Name and location of 11 resettlement camps for former UNITA members and their families included in the survey. (Base map provided by ReliefWeb-UN OCHA on 30 January 2003; modifications by Epicentre on 31 January 2003)

\section{Data collection}

The recall period for assessing mortality was from 21 June 2001 to the survey date (15-31 August 2002), or an average of 427 days. The starting date coincided with a complete solar eclipse visible throughout Angola, thus providing an easily memorable event. We designed standardised questionnaires in Portuguese and Umbundu and piloted them among displaced families north of Luanda before the survey began. Teams of interviewers were formed at each site and trained on the questionnaire by means of role playing. (Copies of the survey manual and questionnaire are available on bmj.com).

Interviewer teams, aided by local translators, conducted face to face interviews with heads of households or, if they were absent, with the most senior adult household member. A household was defined as a group of people sleeping in the same house or sharing meals every day. We collected information on the demographic composition of the household at the start and end of the recall period. We recorded all dates for people joining (newborns, reunifications) or leaving (deaths, disappearances, prolonged absences) the household. A calendar of local events was used to facilitate date recall. For each death reported in the household, we asked the respondent to select one of the following categories as the most likely cause-fever or malaria, diarrhoea, cough, measles, malnutrition, violence or war, or other causes. In depth verbal autopsies were not undertaken, as this method requires rigorous training and adequate time. ${ }^{5}$ Local authorities gave approval for the survey to be conducted.

The data collection process was anonymous, and, to minimise response bias (such as under-reporting of deaths or over-reporting of family size), respondents were clearly informed that the survey was not part of a registration or food distribution process. Oral, informed consent was obtained from all respondents before interviews were started.

\section{Sample size}

We chose a cluster sampling design because the only information available for constructing a sampling frame was a list of resettlement camps and their population sizes (supplied by the United Nations Office for Coordination of Humanitarian Affairs). Survey sample size was determined so as to estimate a crude mortality of 1.5 deaths $/ 10000 /$ day with a $95 \%$ confidence interval of 1.25 to 1.75 (relative precision $16 \%$ ) for a "cluster effect" of two (that is, sample size was calculated for a simple random design and then multiplied by two-experience from previous mortality surveys shows that this is generally sufficient to compensate for intra-cluster homogeneity, a phenomenon not present in simple random surveys). Required sample size was thus 4500 people, corresponding to 900 households (assuming five people per household).

Sampling occurred in three stages. At the first stage, 30 clusters were randomly distributed among the 11 camps proportionally to camp population size. To do this, we divided the total population in the 11 camps by 30 to provide a sampling interval (r), and then built a sampling frame consisting of a list of the camps with a running total of their cumulative population size. We used a random four digit number as the first sampling point on the frame (x), with subsequent points provided by $x+r, x+2 r, x+3 r$, etc, until $x+29 r$. Wherever a point fell on the cumulative population total, a cluster was assigned to the appropriate camp. Thus, a large camp such as Matungo (population 28 094) received six clusters, whereas Ngangasol (population 6834) received only one. At the second stage, the number of clusters assigned to each camp was randomly distributed among the camp's sectors, also proportionally to sector population. At the third stage, we used the standard World Health Organization and Expanded Programme on Immunization (WHO/EPI) method to identify 30 households within each cluster. ${ }^{6}$ We performed second and third stage sampling at the time of data collection as sector population figures could only be obtained from camp authorities on site.

\section{Statistical analysis}

We entered data on EpiData version 2.1 (EpiData Association, Odense, Denmark) and analysed on EpiInfo version 6.04d (Centers for Disease Control, Atlanta, USA). We expressed mortality as the number of deaths/10 000/day. Mid-period population sizes served as denominators:

Mortality= $\begin{gathered}\text { [population at start of period } \\ -0.5 \times(\mathrm{n} \text { people leaving during period }) \\ \\ +0.5 \times(\mathrm{n} \text { people joining during period })]\end{gathered}$

For calculating mortality before and after arrival in a resettlement camp, we used person-days as denominators. Total person-time for the period before arrival in a camp was equal to the sum of the number of days spent by individuals in their respective households between 21 June 2001 and date of arrival in the camps. Total person-time for the period after arrival in a camp was the sum of the number of days spent by individuals in their respective households between arrival in the camp and survey day:

Mortality before or after arrival in camp= $\frac{\mathrm{n} \text { deaths before or after arrival }}{\text { person-days before or after arrival }} \times 10000$ 
We analysed the distribution of causes of death as proportionate mortality. Design effects for each point estimate were computed in CSample, EpiInfo, and applied to calculate $95 \%$ confidence intervals. A crude mortality of $1 / 10000 /$ day, representing a mortality twice normal levels in developing countries, is the threshold commonly applied by relief workers to denote an emergency situation, and we will use it throughout this article to characterise observed mortalities.

\section{Results}

The survey included 900 households, representing 6599 people. All heads of households consented to the interview. At the time of the survey, 5812 people were living in the interviewed households. Their median age was 12 years (range $0-83$ ), with a nearly equal male to female ratio (2850:2962). Children under 5 years old represented $18 \%(1025 / 5812)$ of the sample. The male:female ratio differed markedly by age group: 1.0 (1657:1737) for children under 15 years, 0.8 (947:1171) for ages 15-44, and 4.6 (246:54) for those older than 44.

At the time of the survey, 3592 people (61.8\%) lived in resettlement camps in Cuando Cubango, 1100 $(18.9 \%)$ in Huila, $619(10.7 \%)$ in Bié, and $501(8.6 \%)$ in Malange. Eighty one per cent had arrived in the camps in April or May 2002. Of the 6599 people covered in the survey, 6300 had been present in the household at the time of the solar eclipse. Another 299 people joined the sample during the recall period, while 787 left the household before the time of the survey because of death $(n=390)$, disappearance $(n=42)$, or moving away $(\mathrm{n}=355)$.

\section{Mortality}

The 390 deaths reported during the recall period corresponded to an average crude mortality of 1.5/ $10000 /$ day (95\% confidence interval 1.3 to 1.8$)$. Of these deaths, $182(47 \%)$ occurred in children under 5 , corresponding to a mortality of $4.1 / 10000 /$ day (3.3 to 5.2). Sixty seven $(17 \%)$ of all deaths were reported among children under 1 year old. Of 206 infants born during the recall period, 47 (23\%) had died by the time of the survey. Crude mortality for males was $1.7 / 10000 /$ day (1.4 to 2.1) and for females was 1.3 (1.0 to 1.8$)$.

Monthly crude mortality increased from 0.6/ $10000 /$ day (0.3 to 1.2 ) in June-July 2001 to 2.3 (1.3 to 4.0) in March 2002. After March 2002, mortality decreased but remained higher than in 2001 (fig 2). Crude mortality between 21 June 2001 and arrival in the camps was $1.4 / 10000 /$ day (1.1 to 1.7 ) and for the period after arrival was 1.9 (1.4 to 2.5) (table 1). Mortality in the camps was highest for the first three months after arrival, with 2 deaths/10 000/day, before starting to decline.

\section{Causes of death}

Malnutrition, fever or malaria, and war or violence were the three most frequently reported causes of death (table 2). Malnutrition was among the three top causes of death in all age groups, but children aged under 15 were disproportionately affected. Of the 69 war related deaths, 38 occurred among adult men, 13
Table 1 Crude mortality among former UNITA members and their families before and after their arrival in 11 resettlement camps in Angola (survey period from July 2001 to August 2002, arrival in camps between April and August 2002)

\begin{tabular}{lccc} 
& No of deaths & Person-time in days & Deaths/10 000/day (95\% Cl) \\
\hline Before arrival & 282 & 2034860 & $1.4(1.1$ to 1.7$)$ \\
\hline After arrival: & & & \\
\hline Overall & 108 & 584104 & $1.9(1.4$ to 2.5$)$ \\
\hline 1st month after arrival & 36 & 182245 & $2.0(1.1$ to 3.2$)$ \\
\hline 2nd month & 33 & 174696 & $1.9(1.1$ to 3.2) \\
\hline 3rd month & 29 & 145678 & $2.0(1.1$ to 3.4) \\
\hline 4th month & 9 & 75064 & $1.2(0.4$ to 3.2$)$ \\
\hline 5th month & 1 & 6421 & $1.5(0.0$ to 18.4$)$ \\
\hline
\end{tabular}

among adult women, and 18 among children aged under 15. Overall, war or violence was the leading cause of death in $2001(43 / 126(34 \%))$ but was supplanted by malnutrition in $2002(89 / 264(34 \%))$. Proportionate mortality from malnutrition rose steadily from $15 \%$ in June-September 2001 to $33 \%$ in January-March 2002 and 39\% in April-June 2002. Fever or malaria remained the second most important cause of death throughout the recall period. Differences in proportionate mortality before and after arrival in the camps essentially concerned war or violence (decreasing from 66/280 (24\%) before to $3 / 110(3 \%)$ after) and diarrhoea (increasing from $21 / 280(8 \%)$ before to $21 / 110(19 \%)$ after).

\section{Disappearances}

In total, 42 disappearances were reported during the study period. Of these, 23 occurred among children aged under 15, 11 among women aged 15 and above, and 10 after arrival in the camp. Counting all 42 disappearances as deaths (that is, total number of deaths $=432$ ) increases the crude mortality for the whole recall period to $1.7 / 10000 /$ day (1.3 to 1.8 ).

\section{Discussion}

This retrospective survey provides country level mortality data representative of a large population of former UNITA members and their families displaced within four provinces of Angola. During the 14 months from June 2001 to August 2002, both crude mortality and mortality in children aged under 5 years remained above emergency levels. Mortality among children under 5 was some four times higher than normal, with

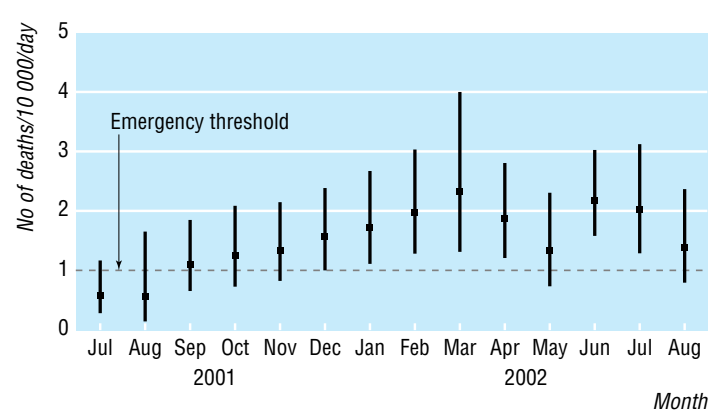

Fig 2 Reported monthly crude mortality (95\% confidence interval) among former UNITA members and their families in 11 resettlement camps in Angola from July 2001 to August 2002. (Mortality of $1 / 10000 /$ day is the threshold applied by relief workers to denote an emergency situation) 
Table 2 Proportionate mortality among former UNITA members and their families in 11 resettlement camps in Angola by age group and reported cause (survey period from July 2001 to August 2002). Values are numbers (percentages) of deaths within age group

\begin{tabular}{|c|c|c|c|c|c|}
\hline & & & Age groups & & \\
\hline & $<5$ years $(n=182)$ & $5-14$ years $(n=91)$ & $15-44$ years $(n=79)$ & $>44$ years $(n=38)$ & All ages $(n=390)$ \\
\hline Malnutrition & $52(29)$ & $44(48)$ & $15(19)$ & $5(13)$ & $116(30)$ \\
\hline Fever or malaria & $61(34)$ & $15(16)$ & $11(14)$ & $7(18)$ & $94(24)$ \\
\hline War or violence & $6(3)$ & $12(13)$ & $37(47)$ & $14(37)$ & $69(18)$ \\
\hline Diarrhoea & $26(14)$ & $10(11)$ & $3(4)$ & $3(8)$ & $42(11)$ \\
\hline Cough & $6(3)$ & 1 (1) & $2(3)$ & $2(5)$ & $11(3)$ \\
\hline Measles & 0 & $1(1)$ & 0 & 0 & $1(0.3)$ \\
\hline Others & $31(17)$ & $8(9)$ & 11 (14) & $7(18)$ & 57 (15) \\
\hline
\end{tabular}

nearly a quarter of all babies born during the recall period dying before the survey.

\section{Limitations of study}

The accuracy of these estimates may have been affected by recall bias, given the unusually long recall period investigated. However, such bias was probably limited by the choice of a solid starting date (all respondents vividly remembered the solar eclipse) and by the systematic placement in the questionnaire of repeated probing questions about mortality.

It is difficult to assess the degree to which survival bias (absence from the sample of households in whom all members either died or could not reach the camps) may have influenced our results. Families of young adult men who had died in armed conflict before arriving in the camps or who preferred not to join demobilisation would probably not have settled in these camps; their mortality experience would therefore not be reflected by the sample.

The observed crude mortality may also not be representative of former UNITA populations living in provinces not surveyed, or of other groups of displaced people. Surveys in open settings are more difficult to carry out, but it has been shown that mortality and malnutrition can be considerably higher among displaced populations not living in camps. ${ }^{89}$

More generally, the WHO/EPI sampling technique (originally conceived for immunisation and nutrition surveys) has not been fully validated as a tool to estimate mortality, and alternative methods have been suggested. ${ }^{10-13}$ Nonetheless, our results are similar to those of other surveys performed during the same period in former UNITA camps in Huambo province (crude mortality 2.3/10 000/day) ${ }^{14}$ and among a displaced population in Bié (crude mortality 1.5/ $10000 /$ day $)^{1.5}$

\section{Implications of results}

In this population, violence was the dominant cause of death up to December 2001. Nearly half of those killed and the vast majority of those who had disappeared were women and children. Our survey results thus confirm reports that civilians were often direct victims of the war in Angola. ${ }^{16}$

Overall, however, malnutrition was the main killer in the study population, an observation mirrored throughout Angola during the 2002 crisis (among adults, it is possible that deaths such as from HIV infection and AIDS and from tuberculosis might have been misreported as malnutrition, but reliable information is lacking on the burden of these infections on the study population). The nutritional emergency peaked between January and June 2002, when hunger was responsible for almost half of reported deaths. Indeed, crude mortality trends run parallel to malnutrition deaths, which show a steady increase from June 2001 to March 2002. The food crisis was aggravated by the surveyed population being inaccessible to relief organisations because of military operations and an embargo on UNITA held areas. The observed crude mortality before the ceasefire is more than double normal levels. Had humanitarian assistance been available, this excess mortality might have been partially limited.

Crude mortality remained high after the ceasefire, when the study population emerged from isolation and settled into camps. Populations tend to have long recovery periods after complex emergencies, particularly after nutritional crises. ${ }^{17} 18 \mathrm{~A}$ follow up survey conducted in camps of former UNITA members in Cuando Cubango province showed that crude mortality remained at $1.1 / 10000 /$ day up to October 2002. ${ }^{19}$ Taken together, our post-ceasefire data suggest that, at least for the first four months of demobilisation in Angola, medical and nutritional assistance to the former UNITA population was insufficient to restore mortality to normal levels. The scarcity and delay in general food distributions after the camps' establishment were probably important factors contributing to the high crude mortality (and correspondingly high proportionate mortality from malnutrition). After 4 April former UNITA populations, already struggling from years of isolation and months of an acute food crisis, were told to assemble rapidly into camps located far from the main roads and urban centres, often surrounded by mined territory, with inadequate water sources and little available means of developing coping strategies such as farming. At the same time, United Nations consolidated appeals for Angola were vastly underfunded, reflecting a general unwillingness on the part of donor agencies to commit to relief programmes during this crisis. ${ }^{20}$ While needs assessments were limited in this context, it seems clear to us that, in the assistance of this displaced population, minimum standards in emergency response were not met. ${ }^{21}$

\section{Conclusions}

This survey documents the impact of war, isolation, and a resulting food crisis on a large population displaced within Angola. Excess mortality of the extent shown here is a constant feature of armed conflicts currently affecting large areas of Africa. ${ }^{22}$ Military and political considerations must not come in the way of effective and timely humanitarian access to populations rendered isolated by such conflicts. 


\section{What is already known on this topic}

In Angola a tentative ceasefire was signed in 2002, bringing 27 years of civil war to an end

After the ceasefire, health assessments conducted among previously inaccessible displaced populations suggested a severe humanitarian crisis

\section{What this study adds}

This retrospective survey, conducted among former members of UNITA and their families living in resettlement camps, documents the effects of violence, isolation, and a food crisis on a large Angolan displaced population

The population experienced high mortality both before and after the ceasefire, mainly due to violence in 2001 and malnutrition in 2002; child mortality was particularly alarming

Military and political considerations should not prevent the delivery of adequate and timely humanitarian assistance to populations in need

We thank all the Médecins Sans Frontières coordination and field teams involved for their help, particularly Fazil Tefera and Sandrina Simons. We acknowledge the invaluable assistance of many Angolan translators, and thank local authorities for their support and hospitality.

Contributors: TG designed the survey with the advice of DL. TG and FC were responsible for the survey in Angola, collected and analysed data, and helped write this report, with the supervision of VB and DL. JME coordinated the survey in Huila Province and helped write this report. Laurence Scoglio coordinated the survey in Soba Matias camp and collected data. Frederic Meylan organised the survey in Kapembe and Matungo camps and participated in data collection, as did Matthias Fromelius, Stefan Kutz, Marie-Helene Mayrand, Mercedes Rocaspana, Patricia Vens, and Eva Verstraete. The survey was a collaborative effort among several sections of Médecins Sans Frontières: CS, AT, and UK supervised and facilitated the survey from their respective headquarters, and helped write this report. DL is guarantor for the study.

Funding: The study was financed entirely by Médecins Sans Frontières.

Competing interests: None declared.

Ethical approval: This study was not reviewed by an ethics committee. Field surveys of mortality in the context of humanitarian emergencies do not go through an institutional review board, and WHO guidelines on mortality assessments do not require an ethical review.

1 Beyond trading insults in international humanitarian aid [editorial]. Lancet 2002;359:2125.

2 Ford N. Slow response to Angola's food crisis. Lancet 2002:360:334

3 Centers for Disease Control and Prevention. Famine-affected, refugee, and displaced populations: recommendations for public health issues. MMWR Recomm Rep 1992;41:1-76.

4 UN Office for Coordination of Humanitarian Affairs (OCHA). Humanitarian situation in Angola: quarterly analysis Aug-Oct 2002. wwww.reliefweb.int/w/rwb.nsf/vID/

F4D310C5F4B9C30F85256C87006CBF39?OpenDocument (accessed 14 Jan 2003).

5 Chandramohan D, Maude GH, Rodrigues LC, Hayes RJ. Verbal autopsies for adult deaths: their development and validation in a multicentre study. Trop Med Int Health 1998;3:436-46.

6 Henderson RH, Sundaresan T. Cluster sampling to assess immunisation coverage: a review of experience with simplified sampling method. Bull WHO 1982;60:253-60.

7 World Health Organization. Rapid health assessment protocols for emergencies. Geneva: WHO, 1999.

8 Bhutta ZA. Children of war: the real casualties of the Afghan conflict. BMJ 2002;324:349-52.

9 Aaby P, Gomes J, Fernandes M, Djana Q, Lisse I, Jensen H. Nutritional status and mortality of refugee and resident children in a non-camp setting during conflict: follow-up study in Guinea-Bissau. BMJ 1999;319:878-81.

10 National Research Council. Demographic assessment techniques in complex humanitarian agencies: summary of a workshop. Washington, DC: National Academy Press, 2002

11 Boss LP, Toole MJ, Yip R. Assessments of mortality, morbidity, and nutritional status in Somalia during the 1991-1992 famine. Recommendations for standardization of methods. JAMA 1994;272:371-6.

12 Robinson WC, Lee MK, Hill K, Burnham GM. Mortality in North Korean migrant households: a retrospective study. Lancet 1999;354:291-5.

13 Salama P, Assefa F, Talley L, Spiegel P, van Der Veen A, Gotway CA. Malnutrition, measles, mortality, and the humanitarian response during a famine in Ethiopia. JAMA 2001;286:563-71.

14 Brown V. Evaluation de la situation nutritionnelle, de la mortalité, et de la couverture vaccinale contre la rougeole. Trois sites de cantonnement de Chiteta, Municipio de Bailundo, Angola, June 2002. Paris: MSF/ Epicentre, 2002.

15 Grein T, Checchi F. Mortality among internally displaced persons in Camacupa municipality. Bié Province, Angola, August 2002. Paris: MSF/ Epicentre, 2002.

16 Stokes C, Ford N, Sanchez O, Perrin J-M, Poncin M, Joly M. Angola's suffering behind a pretence of normality. Lancet 2000;356:2093-4.

17 Burkholder BT, Toole MJ. Evolution of complex disasters. Lancet 1995;346:1012-5.

18 Toole MJ, Waldman RJ. The public health aspects of complex emergencies and refugee situations. Annu Rev Public Health 1997;18:283312.

19 Borel T, Gaboulaud V. Mortality, nutritional and measles vaccination status among populations in Mavinga town and in UNITA resettlement status among populations in Mavinga town and in UNITA resettlement
areas (Matungo and Capembe). Angola, November 2002. Paris: areas (Matungo and
MSF/Epicentre, 2002

20 De Mul E. Coordination of humanitarian aid-a UN perspective. Lancet 2002;360:335-6

21 The Sphere Project. Humanitarian charter and minimum standards in disaster response. www.sphereproject.org (accessed 18 Apr 2003).

22 Murray CJL, King G, Lopez AD, Tomijima N, Krug EG. Armed conflict as a public health problem. BMJ 2002;324:346-9.

(Accepted 12 May 2003) 